\title{
ARTE-EDUCAÇÃO EM PSICOLOGIA: A MÚSICA COMO AÇÃO E MECANISMO DE COMPREENSÃO NO PROCESSO CRIATIVO- INTERVENTIVO FRENTE A CONFLITOS EMOCIONAIS NA EDUCAÇÃO SUPERIOR
}

\author{
Maria Jucilene Silva Guida de Sousa \\ UEMA
}

\section{Resumo}

Este trabalho, Arte-educação em Psicologia: a Música como ação e mecanismo de compreensão no processo criativo-interventivo frente a conflitos emocionais na Educação Superior visa abordar Arte-Educação em Psicologia como estratégia de inovação em Educação Superior, pois acreditase que, por meio do preparo psicológico do aluno é possível ajudá-lo a enfrentar suas dificuldades de aprendizagem no contexto acadêmico e, consequentemente diminuir o índice de evasão e reprovação na Educação Superior. Duas ferramentas que se complementam neste sentido é a Música, como Ciência e como subárea de Artes atrelada à Abordagem Centrada na Pessoa $(\mathrm{ACP})$, teoria do Psicólogo Carl Rogers. Algumas Universidades brasileiras já disponibilizam o trabalho psicopedagógico ao educando, no entanto ainda é um trabalho tímido, diante da grande necessidade evidenciada pelos educandos. Por intermédio da Pesquisa Bibliográfica e da Pesquisa-Ação buscouse efetivar este trabalho científico, que ressalta a importância de um trabalho interdisciplinar entre Educação, Psicologia e Música e descreve a prática psicopedagógica da autora deste trabalho, quando da sua gestão no Curso de Música Presencial da Universidade Estadual do Maranhão.

\section{Palavras-chave:}

Música; ACP; Educação Superior.

\section{INTRODUÇÃO}

É possível estudar Arte-educação em Psicologia, num processo interdependente e dialógico, sem que nenhuma delas perca sua essência, já que todas elas priorizam o sujeito em suas diferenças. Este trabalho enfatiza a Arte-

\section{Abstract}

This work, Art-education in Psychology: Music as an action and mechanism of understanding in the creative-intervention process in the face of emotional conflicts in Higher Education aims to approach Art Education in Psychology as a strategy of innovation in Higher Education, by means of the psychological preparation of the student it is possible to help him to face his learning difficulties in the academic context and, consequently, to reduce the rate of evasion and disapproval in Higher Education. Two complementary tools in this regard are Music, as Science and as subarea of Arts tied to the PersonCentered Approach (ACP), theory of Psychologist Carl Rogers. Some Brazilian universities already offer psychopedagogical work to the student, however it is still a timid job, given the great need evidenced by the students. Through the Bibliographic Research and Research-Action, it was tried to carry out this scientific work, which emphasizes the importance of an interdisciplinary work between Education, Psychology and Music and describes the psychopedagogical practice of the author of this work, when her management in the Music Course Faculty of the State University of Maranhão.

Keywords:

Music; ACP; College Education.

educação em Psicologia na Educação Superior, haja vista que há uma necessidade urgente de inovações no que se refere a qualidade do ensino e da aprendizagem no contexto acadêmico. Dessa forma, a Música como subárea de Artes e como Ciência se constitui em possibilidades de intervenção psicopedagógica nas dificuldades 
de aprendizagem dos educandos de ensino superior; mas como fazer um trabalho dentro de um espaço de tempo tão restrito como o tempo do estudante universitário? Esta inquietação por parte da autora deste trabalho fez com que buscasse fundamentação na Abordagem Centrada na Pessoa (ACP), de Carl Rogers, a qual visa ajudar o ser humano a se sentir aceito, pois a aceitação de si mesmo o leva a autorrealização.

Este artigo surge da prática pedagógica da autora, em sua função de Psicóloga e Psicopedagoga no Curso de Música Licenciatura Presencial, quando da sua gestão de Diretora do referido curso, ou seja, por meio de atividades envolvendo música conseguiu ajudar muitos alunos com dificuldades de aprendizagem, por intermédio do atendimento personalizado baseado na ACP de Carl Rogers. A partir da sua experiência profissional foi articulado o seguinte questionamento, que se constitui no problema gerador do trabalho: quais as possibilidades de utilização da Música atrelada a Abordagem Centrada na Pessoa (ACP) de Carl Rogers como processos de compreensão de conflitos emocionais e intervenção psicopedagógicos, na Educação Superior?

Diante dessa problemática articulou-se o objetivo geral, que é refletir sobre o fazer arte-educação de um psicólogo, por meio de atividades musicais no processo criativointerventivo a conflitos emocionais de alunos da Educação Superior e ainda, como objetivos específicos, compreender a abrangência do fazer psicopedagógico na Educação Superior, reconhecer a contribuição da Música e da ACP de Carl Rogers como possibilidades de intervenção nas dificuldades de aprendizagem de alunos. Elegeu-se como procedimento metodológico, a Pesquisa Bibliográfica e a Pesquisa-ação.

\section{A ACP DE CARL ROGERS E A MÚSICA NO PROCESSO DE INTERVENÇÃO DAS DIFICULDADES DE APRENDIZAGEM DE ALUNOS DO ENSINO SUPERIOR}

Considera-se relevante pesquisar o tema: "ArteEducação em Psicologia porque entende-se que "toda genuína representação artística é em si mesma o universo, o universo naquela forma individual, aquela forma individual como o universo" (ECO, 2013, p.51); por meio destas palavras de Humberto Eco pode se compreender um pouco da Teoria do psicólogo Carl Rogers, a qual valoriza a individualidade, a percepção e o ritmo do ser humano ao lidar com suas emoções e comportamentos aprendidos, pois a "emoção está ligada a sentimentos e estes são afetados pela prática musical que- quanto mais prazerosamais estimula a química cerebral, propiciando respostas comportamentais" (LOURO, 2016, p.90). Essas respostas comportamentais estão relacionadas à forma como o indivíduo se percebe e aos conceitos que internaliza de si mesmo. "Será que temos consciência do potencial a ser desenvolvido na pessoa quando trabalhamos a linguagem musical?" (DAUD, 2009, p. 07). É neste contexto que a Abordagem Centrada na Pessoa, de Carl Rogers se constitui como embasamento para a prática interventiva do profissional da educação no processo de aprendizagem do aluno da Educação Superior (MELLO:2011), pois "o indivíduo tem dentro de si amplos recursos para autocompreensão, para alterar seu autoconceito, suas atitudes e seu comportamento autodirigido" (ROGERS, 1989, p.16).

Muitos estudiosos buscaram definir Arte, embora se saiba que conceituá-la de maneira clara e concreta sempre será um ato incompleto. Enquanto Herbert Read (1958) conceitua Arte como "expressão" e estimula modificações a nível de sentimentos, Vigotsky (1970) a define como "técnica social do sentimento" e E. Soureau (1973) disse que somente "a Arte exprime os sentimentos informuláveis" (CASTELÃO, 2011). É neste contexto subjetivo de significados que a Psicologia exerce influência na Arte e é influenciada por ela, haja vista que a Arte possui funções psicológicas e promove benefícios psicológicos, que ajudam o sujeito a construir sua aprendizagem.

A arte-educação, parte do pressuposto de que "os estudiosos nesta área não têm como finalidade produzir objetos artísticos propriamente ditos, nem fazer apresentações públicas, mas sim colocar fenômenos artísticos ao serviço da Educação e das experiências terapêuticas (GOHN, 2003). Assim, o estudo de Arte-educação em Psicologia implica em práticas de auxílio ao indivíduo no processo de construção de seu conhecimento, por meio da recreação, socialização e o desenvolvimento pessoal. (LEONTIEV, 2000). 
Se existe uma palavra que caracteriza bem - fazer psicopedagógico, essa palavra é criatividade. Pelo fato de não haver receitas prontas para o processo de intervenção, pois cada dificuldade de aprendizagem diagnosticada exige uma postura peculiar por parte do psicopedagogo, que por sua vez, se vê diante de situações diferenciadas em relação aos sujeitos do aprender, os quais são singulares, mesmo apresentando problemas parecidos. "É verdade que o tipo de atenção ou de inteligência varia bastante de pessoa a pessoa. Às vezes somos bem expertos, outras vezes um pouco lentos e desatentos". (LUCAS, 2005, p. 13-14).

O papel da intervenção psicopedagógica é o "de provocar situações, nas quais aprender passa a ser interessante e consequentemente prazeroso" (BARBOSA, 2006, p.25) e, uma das formas de conseguir isso é pela utilização da música, pois esta é movimento e "toda conduta supõe uma ação, um movimento interno ou externo; no primeiro caso poderá ou não refletir-se em algo externo ou observável: gesto, movimento, som, rubor, alteração da pulsação ou da pressão sanguínea" (GAINZA, 1988, p.21).

Toda intervenção psicopedagógica traz - ou pelo menos deve trazer - em seu bojo, a finalidade de promover a felicidade do aprendente, logo a alegria de sentir útil, vivo e importante no processo é condição impreterível, sem a qual não haverá eficácia, nem efetividade no processo de aprendizagem. Segundo Gainza (1988, p. 95): "Educar-se na música é crescer plenamente e com alegria. Desenvolver sem dar alegria não é suficiente. Dar alegria sem desenvolver tampouco é educar". Isso não significa necessariamente, que se deve desprezar o fato de que a aprendizagem acontece também por meio da dor, mas a finalidade última é o prazer, a alegria de ter alcançado a superação diante das dificuldades apresentadas.

\section{DESCRIÇÃO DA PESQUISA-AÇÃO DESENVOLVIDA NO CURSO DE MÚSICA LICENCIATURA PRESENCIAL DA UEMA}

Durante os dois anos de sua gestão no Curso de Música Presencial da Universidade Estadual do Maranhão - UEMA, a autora deste trabalho desenvolveu uma pesquisa em que ao mesmo tempo foi sujeito e objeto desta, ou seja, foi feita uma Pesquisa-Ação, que segundo Thiollent (1988) é um tipo de investigação social com base empírica, que é concebida e realizada, por meio de uma ação ou com a resolução de um problema coletivo, no qual pesquisador e participantes estão envolvidos, de maneira colaborativa.

Na sua condição de Psicóloga e Psicopedagoga e de Gestora do Curso de Música presencial, a autora percebeu um índice de evasão significativa no curso e, por meio de entrevista e observações percebeu que muitos alunos não tinha muita perspectiva otimista quanto ao término do curso, devido a inúmeros motivos, tais como: relacionamento professor-aluno, dificuldade de base de conhecimento, questões econômicas, pois alguns precisavam trabalhar no mesmo turno que funcionava e ainda funciona o curso, dificuldades de conciliar os estudos com conflitos emocionais diversos e etc.

Assim, a autora deste trabalho resolveu disponibilizar aos alunos, de maneira gratuita o seu serviço psicopedagógico, o qual foi desenvolvido de acordo com a demanda dos alunos, nos seus horários vagos ou pelas suas necessidades mais urgentes. O trabalho funcionou na única sala que o Curso dispunha, onde eram feitas reuniões dos professores. No início percebeu-se muito preconceito por parte de alguns alunos, pela ideia de que o trabalho psicopedagógico pudesse expô-los com as suas necessidades, mas depois de entenderem a seriedade e a ética no processo do Serviço de Orientação Educacional e Psicológico - SOEP, proposto pela professora Assistente II do Curso de Música, Maria Jucilene S. G. de Sousa, os alunos começaram a buscar o atendimento.

As sessões no atendimento individual duravam de 30 a 45 minutos e, além de Orientações de cunho cognitivo eram dadas orientações de cunho emocional, as quais baseavamse na Abordagem entrada na Pessoa de Carl Rogers, que visa ajudar os alunos a utilizarem seus recursos internos e externos para se autoconhecerem e serem sujeitos de seu processo de aprendizagem. Todavia, a profissional não parou somente com a utilização da ACP, mas resolveu buscar na Música possibilidades de resultados mais dinâmicos durante as sessões. 
Já se sabe que não existe falta de interesse em aprender por parte do aluno, o que existe é ausência de uma estratégia adequada para ser executada para seu problema específico. Neste sentido, a intervenção remediativa do psicopedagogo/psicólogo se amplia com a relação entre o sujeito, sua história pessoal e a sua categoria de aprendizagem. Já o trabalho preventivo, objetiva distanciar o máximo possível os problemas de aprendizagem, contribuindo com a instituição nos processos didáticos e metodológicos, na dinâmica institucional com todos os envolvidos no processo.

\section{ALGUMAS ATIVIDADES DESENVOLVIDAS NA PESQUISA-AÇÃO}

O trabalho de intervenção por meio da música pode ser associado a algumas premissas teóricas estudadas pelo professor Feuerstein. Ele foi um estudante de Psicologia que começou a examinar a questão sobre a Modificabilidade Humana. (DA ROZ, 2002).

As premissas estudadas por Feuerstein são Modificabilidade Cognitiva Estrutural - MCE, Experiência de Aprendizagem Mediada - EAM, Mapa Cognitivo, Operações Mentais, Funções Cognitivas, Privação Cultural, Avaliação Dinâmica da Propensão à Aprendizagem (LPAD), Programa de Enriquecimento Instrumental (PEI) e Ambientes Modificantes. Para efeitos didáticos, serão descritas apenas as três primeiras na pesquisa-ação desenvolvida pela autora deste trabalho.

\section{A MODIFICABILIDADE COGNITIVA ESTRUTURAL (MCE)}

Feuerstein (1991) apud Battistuzzo (2009, p. 15-16) define Modificabilidade (cognitiva) como "a propensão (potencial) de um indivíduo se modificar através de ambas as experiências de aprendizagem direta e mediada direcionadas para necessidades estruturais e comportamentais". Por modificação entende o resultado dos processos de desenvolvimento e maturação física. A modificabilidade refere-se à mudança estrutural que se processa na mente de uma pessoa. Dessa forma, se faz necessário ocorrer desconstrução e/ou desconstrução de significados ou de palavras, de acordo com o contexto em que o indivíduo está inserido.
Em contextos diferentes a palavra muda facilmente de sentido. O significado, ao contrário, é um ponto imóvel e imutável que permanece estável em todas as mudanças de sentido da palavra em diferentes contextos. Foi essa mudança de sentido que conseguimos estabelecer como fato fundamental na análise semântica da linguagem (Vigotski, 1934/2001, p. 465).

Um exemplo prático trabalhado com um aluno do $8^{\circ}$ período foi com o jogo do balão rítmicomusical que pode ser trabalhado tanto com crianças quanto com adultos e ainda, pode ser realizada de forma individual ou em grupo. 0 aluno sofria de autoestima baixa e ansiedade, ou seja, o pensamento que tinha sobre si mesmo era negativo e decadentista, além de potencializar crenças de fracassos naquilo que poderia "vira-ser" em sua vida. O objetivo da atividade era buscar descontruir significados e pensamentos que fortalecia sua autoestima baixa. Pois, concorda-se com Vigotsky (1934/2001, p. 481) que para entender o discurso do outro, "nunca é necessário entender apenas umas palavras; precisamos entender o seu pensamento. Mas é incompleta a compreensão do pensamento do interlocutor sem a compreensão do motivo que o levou a emiti-lo". Assim, foi com o jogo do balão, que pode ser trabalhado tanto para crianças, quanto para adultos e ainda pode ser realizada de forma individual ou em grupo.

A psicóloga e especialista em psicopedagogia pediu para que o aluno enchesse o balão, de acordo com o ritmo da música, hora mais acelerada, hora mais lenta. A bexiga foi cheia de ar até certo ponto, a fim de não explodir. Depois foi orientado ao acadêmico que o esvaziasse devagar. Finalmente, voltou a enchê-lo e brincou com o balão fazendo gestos rítmicos de acordo com sua criatividade.

O desenvolvimento do jogo com o auxílio de música - seja ela acelerada ou lenta - influirá sobre o aprendente, um estímulo mais evidente porque atingirá seus sentidos como um todo, fazendo construir representações mentais significativas, ou seja, a busca por encontrar seu ritmo será auxiliada pelo ritmo da própria música utilizada, ou esta servirá de termômetro para o psicopedagogo verificar o ritmo contrastante do aprendente ao ritmo mais ideal. Depois do processo dinâmico, passou-se a orientação sobre o potencial do aluno e seu poder de autocontrole no processo de tomada de suas decisões. 


\section{EXPERIÊNCIA DE APRENDIZAGEM MEDIADA (EAM)}

A intervenção psicopedagógica com o auxílio de música está alicerçada nesse processo de aprendizagem, no qual o aprendente recebe o auxílio de outro ser humano, que por sua vez, se sente capaz de se envolver responsavelmente nesse tipo de experiência. Aqui a ACP, de Carl Rogers é intimamente ligada com a Música.

As duas formas são interdependentes, a aprendizagem mediada é pré-requisito para a aprendizagem direta. A partir do momento em que o sujeito que aprende se depara com dificuldades de aprendizagem ele se vê amparado pela ajuda do educador, isto é, ambos se constituem responsáveis pelo processo. Por outro lado, se o profissional apenas transmite informações não conseguirá ajudar o aluno construir hipóteses e muito menos auxiliá-lo na tomada de decisões.

Outro exemplo prático, que pode ser explicitado nesse contexto é o jogo da "Vela", que serve para o especialista, observar bem se um aluno está conseguindo relaxar ou não, e ainda, se consegue acompanhar o jogo, se não possui imaginação correlata à situação que está inserida. Esta atividade foi desenvolvida a um aluno ( $5^{\circ}$ período), que acabara de perder um irmão e não conseguia se concentrar nas aulas.

Articulou-se a atividade assim: o facilitador colocou com tranquilidade e um pouco afastada, uma vela em frente ao acadêmico e acendeu. Depois pediu para ele observar a vela, o que acontece com ela quando for assoprada, depois bater palmas perto da chama, ou se ele pular perto da vela, etc., depois pediu para que o discente em silêncio imagine que ele é a vela, levantando, esticando os dois braços, juntando as mãos por cima da cabeça (imitando a chama). Só a partir deste momento o psicopedagogo começou dar orientações mais específicas para que o aluno pudesse desenvolver sua criatividade (abre-se uma janela, entra ar e a vela se move, se consome e fica pequenininha, pequenininha, cada vez menor; depois abremse duas janelas e a vela se apaga etc). Esta atividade foi feita com a música "Dear John Ost" de Déborah Lurie. Esta atividade feita sem música pode exigir um esforço muito maior - gerando um risco de ter uma sensação de impotência - por parte do ser que aprende. Entretanto se feita com músicas diferentes de preferência instrumentais, se constituirá matéria-prima para que a imaginação do aluno possa fluir com mais êxito.

\section{MAPA COGNITIVO}

O Mapa cognitivo é uma ferramenta de extrema relevância na intervenção psicopedagógica que visa relacionar as características de uma determinada tarefa ao desempenho do raciocínio de uma pessoa. "Mapa Cognitivo é um modelo para analisar as dimensões de uma tarefa de aprendizagem e as operações mentais exigidas e como elas contribuem para uma compreensão das funções cognitivas do indivíduo, sua resposta à mediação, e o potencial de modificabilidade" (FEUERSTEIN; FALIK; FEUERSTEIN, 1991 apud BATTISTUZZO, 2009, p. 26). Mapa cognitivo é, portanto, a representação gráfica de uma representação mental, ou seja, é um enunciado de um discurso expresso por um sujeito, que por sua vez, possui suas próprias representações cognitivas frente a um objeto específico. Uma das muitas possibilidades de construir um mapa cognitivo com o auxílio de música é pela técnica da "Construção mental da casa dos sonhos" e da técnica "Poderia Ser" (LUCAS, 2005).

Uma aluna do $3^{\circ}$ período do curso de Música presencial, com incerteza de sua capacidade de continuar o Curso, chegou apresentando esta demanda e foram desenvolvidas três sessões com orientações personalizadas e pela atividade do Mapa Cognitivo.

A psicopedagoga e Psicóloga solicitou à aluna que desenhasse mentalmente a "casa dos seus sonhos" (LUCAS, 2005, p. 104) com sua ajuda, pedindo que relaxasse (mediante as técnicas de relaxamento com música, na qual o especialista diz: Essa casa fica diante de um lago tranquilo e calmo, nela você se sente seguro, relaxado, cheio de energia e criatividade. Assim que terminar de construí-la ela será o refúgio onde entrará em contato com seu ser inteligente (quando precisar ou apenas para se divertir). A atividade inicial objetivou o exercício da reflexão, aqui "entendida como ato mental de reconstrução e reorganização sobre o patamar superior daquilo que foi assim transferido do inferior" (PIAGET, 1995, p. 274). 
A psicóloga/psicopedagoga pediu à aluna que em algum momento da construção da casa ela cantasse fragmentos de músicas que conhecia e que tinha a ver com a sensação que ela sentia naquele instante. Na sessão seguinte de atendimento feito pela psicopedagoga e psicóloga, a aluna trouxe uma das músicas completa - que ela inferiu (só em fragmentos) na construção de sua casa dos sonhos (conhecimento de ponto de referência), a partir daí ele iria reescrevê-la (conhecimento rotaestrada). Depois dessa atividade envolvendo música a aluna afirmou ter condições suficientes para pensar em alguma situação que the causava dificuldade e descrevê-la numa folha de papel. Ela conseguiu construir possibilidades. Conforme afirma Piaget (1981, p. 07):

\begin{abstract}
Com efeito, o possível não é algo observável, mas o produto de uma construção do sujeito em interação com as propriedades do objeto, mas inserindo-as em interpretações devidas às atividades do sujeito, atividades essas que determinam, simultaneamente, a abertura dos possíveis cada vez mais numerosos, cujas interpretações são cada vez mais ricas.
\end{abstract}

Ela fez o mesmo procedimento que já havia ensaiado com a música, agora o foco era seu relato. Posteriormente, a aluna decidiu que iria continuar o curso, mas com uma perspectiva mais otimista.

Objetivou-se com esses exemplos práticos mostrar apenas "gotas de águas" frente a um "oceano de possibilidades" existentes não só em relação aos recursos psicopedagógicos apresentados, mas diante de outros, como o psicodrama, os livros sem texto, a caixa de areia e outros, os quais se tornarão mais expressivos com a utilização de música pautada na criatividade do psicólogo ou psicopedagogo.

\section{CONSIDERAÇÕES FINAIS}

Diante da situação-problema apresentada inicialmente neste trabalho, por meio da indagação: quais as possibilidades de utilização da Música aliada à Abordagem Centrada na Pessoa (ACP) de Carl Rogers como processo de intervenção psicopedagógico, na Educação Superior? Percebeu-se, que devido à prática psicopedagógica se sustentar na intenção de compreender a formação da pessoa, frente a sua predisposição para aprender, os dois aspectos, afetividade e inteligência se constituem em pano de fundo para a utilização da Música e da ACP como processos de intervenções psicopedagógicos, pois ambas penetram profundamente nas sensações do indivíduo possibilitando o seu agir por meio de seleções cognitivas seguras e conscientes.

Verificou-se que a música como linguagem permite - a quem a utiliza pedagogicamente diferentes formas de comunicar, o que implica em invenção e reinvenção de outras linguagens e em transformação do mundo interior e exterior dos elementos humanos (ACP) (ROGERS:2004) envolvidos no processo de aprendizagem do educando do Ensino Superior, no que se refere ao plano cognitivo, psicológico e social.

Sugere-se a implantação do Trabalho Psicopedagógico feito pelo Psicólogo especialista em todos os cursos da Universidade Estadual do Maranhão, pois essa inovação implicará em maior qualidade no processo de ensino-aprendizagem, além de minimizar os índices de evasão e reprovação, recorrentes na graduação desta IES.

\section{REFERÊNCIAS}

BARBOSA, Laura Monte Serrat. Psicopedagogia: um diálogo entre a psicopedagogia e a educação. 2 ed. Curitiba: Bolsa Nacional do Livro, 2006.

BATTISTUZZO, Lígia Helena Coldana. Experiência de Aprendizagem Mediada de Reuven Feuerstein: A modificabilidade em alunos de cursos profissionalizantes. Universidade de Sorocaba: São Paulo, 2009.

CASTELÃO, Maria Luzia Lopes. Arte-educação: a mediação Cultural e o Trabalho com Equipas Criativas. Dissert. Mestrado. Universidade de Lisboa: Instituto de Educação, 2011.

DAUD, Alliana. Jogos e Brincadeiras Musicais. São Paulo: Paulinas, 2009.

ECO, Humberto. A Estrutura Ausente: Introdução à Pesquisa Semiológica. São Paulo: Perspectiva, 2013.

DA ROZ, Silvia Zanatta. Pedagogia e mediação em Reuven Feuerstein: o processo de mudanças 
em adultos com história de deficiência. São Paulo: Plexus, 2002.

GAINZA, V. Hemsy de. Estudos de Psicopedagogia Musical. São Paulo: Summus, 1988.

GOHN, Daniel Marcondes. Autoaprendizagem Musical. São Paulo: Annablume, 2003.

LEONTIEV, D. Funções da Arte-educação Estética. In educação Estética e Artística: Abordagens transdisciplinares. Coordenação: Frois, Fundação C: Golauste Gulbenkion, 2000.

LOURO, Viviane (org). Música e Inclusão: Múltiplos olhares. São Paulo: Editora Som, 2016.

LUCAS, Bill \& CLAXTON, Guy. Criative-se; um guia prático para turbinar o seu potencial criativo. São Paulo: editor Gente, 2005.

MELLO, Maria Ines de Souza Azevedo. A música como instrumento de intervenção psicopedagógica. $V$ ENLETRARTE: Campo dos Goytacazes/RJ, 2011.

PIAGET, J. Abstração reflexionante. Porto Alegre: Artes Médicas, 1995.

Le possible et le nécessaire: l'evolution des possibles chez l'enfant. Paris: Presses Universitaires de France, 1981

ROGERS, Carl. Sobre o Poder Pessoal. $3^{a}$. Edição, S. Paulo, Martins Fontes Editora, 1989.

Carl. Terapia Centrada no Cliente.

Trad. Lisboa Moraes Editores, 2004.

THIOLLENT, M. Metodologia da Pesquisa-ação. São Paulo: Cortez \& Autores Associados, 1988.

VIGOTSKI, L. S. (2001). Pensamento e palavra. In L. S. Vigotski. A construção do Pensamento e da Linguagem. São Paulo: Martins Fontes. (Original publicado em 1934).

\section{SOBRE A AUTORA}

Maria Jucilene Silva Guida de Sousa é Psicóloga Clínica (CRP: 22/02106), Doutoranda em Arteeducação: Psicologia e Música (UFPA), Pedagoga, Graduada em Letras Português-Inglês, Bacharel em Teologia, Graduada em Música. É Mestre em Língua Portuguesa, Mestre em Educação, Especialista em Libras, Especialista em Psicopedagogia Clínica, Especialista em Metodologia do Ensino Superior, Especialista em Mídias na Educação, Especialista em Orientação Educacional, Especialista em Aconselhamento e Cuidado, Especialista em Avaliação Psicológica, Especialização em Neuropsicologia (cursando). Atualmente é Professora Assistente II no Curso de Música da Universidade Estadual do Maranhão (UEMA), é Psicóloga Clínica e Psicopedagoga clínica no Núcleo de Atendimento Cognitivo-Comportamental- Néfesh , é Cantora profissional, Coordenadora do Curso de Música EAD da UEMA em São Luis_Ma. E-mail: jucilenelise@gmail.com. 